\title{
Industrial Engineers of the Future - A Concept for a Profession that is Evolving
}

\author{
Piwai Chikasha, Kemlall Ramdass, Ndivhuwo Ndou*, Rendani Maladzhi, Kgabo Mokgohloa
}

University of South Africa, Department of Mechanical and Industrial Engineering, Johannesburg, 2038, South Africa

\begin{tabular}{l} 
A R T I C L E I N F O \\
\hline Article history: \\
Received: 21 February, 2021 \\
Accepted: 26 May, 2021 \\
Online: 10 July, 2021 \\
\hline Keywords: \\
Industrial engineering \\
Innovation \\
Sustainability \\
Digital technologies \\
\end{tabular}

\begin{tabular}{l} 
A B S T R A C T \\
\hline Just as industry is dynamic, constantly evolving according to the state of technology, \\
economics, politics and so on, so must be, higher education. Studies have shown that higher \\
education, for the past century, has constantly adapted to the dynamic skill and knowledge \\
requirements of industry. This adaptation, however, is not always timeous and precise \\
resulting in a widening gap between industry skill requirements and the skills that \\
graduates receive during tertiary learning. This gap can be narrowed if higher education \\
develops futuristic models that prepare students for not only the present day, but the future \\
as well. Higher education in the fields of science, technology and engineering in particular, \\
are in critical need of this future-prediction approach given the high levels of constant, and \\
in some cases, even accelerating change or dynamics. This study develops a concept for \\
industrial engineers of the future and demonstrates that is it possible to better prepare \\
graduates for the uncertain future, by predicting some key skill requirements of industry \\
ahead of time from information ofyesterday and today.
\end{tabular}

\section{Introduction}

To enrol students for the Industrial Engineering qualification, and to provide the students with education for the set number of years, without taking in to account, the future of the profession, would be unfair practice. The same is in fact true for many other higher education qualifications, especially those in engineering. The reason for this is the dynamic nature of industry, the economy and even society as we know it. In the twenty-first century, it is therefore critical that higher education incorporates aspects of the futuristic profession, into the lessons of today, for the benefit of not only the students, but also the respective industry, and not only for today, but tomorrow as well.

This study discusses the concept of 'industrial engineers of the future'. It is well understood that the industrial engineering profession today is not as it was ten years ago. Similarly, the industrial engineering profession of 2030, ten years from now, may not be as that of the present day. If then, the higher education system is preparing tomorrow's engineers today, a tomorrow that presents different challenges demanding different solutions, substantial effort is required in ascertaining tomorrow's industry characteristics in today's education program.

In [1], the author elaborates that industrial engineering is multidisciplinary, fully fledged and increasingly becoming more and

*Corresponding Author: Ndivhuwo Ndou, Email: mokgok@unisa.ac.za www.astesj.com

https://dx.doi.org/10.25046/aj060409 more dynamic. The author points out that the growth of this profession was expedited in the twentieth century by the manufacturing sector, as well as government and service enterprises. The industrial engineering profession is widely understood to be dynamic, with a future dependent not only on the ability of the engineers to meet the respective economic and industrial operational demands, but also dependent on the ability of the engineers to innovate and actually drive the economic and industrial operational trends. To best answer the research questions, it is necessary to first approach the study from a more general point of view, considering the engineering discipline as a whole.

Technology is one certain part of engineering, that continues to evolve with time. This has been the case even over the past century. Curriculum therefore needs to prepare future engineers for a work environment that is in constant evolution, characterized by constant updates to the technologies used in engineering. In [2], this constant evolution is presented, demonstrating where the profession of industrial engineering is coming from.

This paper contributes to the question of where the profession is headed. Taking the software engineering profession for example, open-source technologies are topical and are highlighted as a basis for the future engineer. In [3], the author discusses artificial intelligence as having reshaped technology significantly over the past decades, and being posed for future dominance. Such 
are the factors to consider in ensuring that students today, are optimally oriented for tomorrow.

In [4], the author demonstrates how the future of engineering is one closely aligned to environmental sustainability as well as the well-being of humans. With growing demand for technologies, products and systems that are environmentally friendly and health friendly are also seeing growth in demand. This briefly demonstrates that engineering is not static but rather dynamic. If the trends of engineering can be anticipated or predicted, it is in the best interest of the students and overall economy and industry.

\subsection{Problem statement}

Conventionally, South African higher education is not adequately future oriented or future proof. This contributes to education lagging behind the dynamics of industry instead of overtaking industry in order to shape-out society and technological trends. The problem is that higher education lacks robust systems and mechanism that are capable of identifying and strategically accommodating elements of the future of the respective profession into today's education.

\subsection{Research question}

Given the dynamic nature of industry, can we develop a concept for industrial engineers of the future, in order to provide career-oriented future-proofing for industrial engineering graduates? What are the key factors to consider when developing the concept of industrial engineers of the future?

\subsection{Concluding remarks to introduction}

The paper is structured as (a) Introduction which provides some background information of the research, as well as the problem statement and the research question. (b) Literature review (c) Research methodology (d) Discussion and findings; and (e) Conclusions and recommendations. The literature review provides a view of some aspects of the industrial engineering profession that form a strong basis for the future of the profession. The research methodology therefore pivots on these aspects to create a complete concept.

\section{Literature review}

The literature survey of this work is structured to initially assess past trends of the industrial engineering profession. The idea is to appreciate the fact that the profession is indeed dynamic, shifting decade after decade in terms of skill areas. The next step then, is to establish a projection of the competences that will shape the industrial engineering profession of tomorrow.

\subsection{Industrial engineering trends}

The industrial engineering profession, as hinted by the title, is industry driven. In [5], the author illustrates how the future of industrial engineering is heavily influenced by customer demands and expectations. The demands and expectations of the customer are on a trajectory of rapid growth, giving rise to the need for constant improvement in production processes as well as operational systems, in order to minimize cost yet maximizing quality. Industrial engineering is key in realizing this goal.
In [6], authors show that Internet of Things (IoT) is a key part of tomorrow's industry. Industrial engineers of the future are therefore expected to embrace the concept of IoT. At curriculum level, it is presented that it is necessary to adjust curriculum to take more consideration of IoT in order to produce graduates who are more oriented for the work environment of today and also tomorrow.

In [7], the authors explore the value of interdisciplinary competences to the future of industrial engineering. It is shown that, due to the diversity of industrial engineering work, which continues to evolve, interdisciplinary skills are a critical aspect. A teaching method which emphasizes interdisciplinary scope and teamwork is proposed. In [8], the authors explicitly demonstrate how approaching engineering from an interdisciplinary perspective promotes technological development for national prosperity.

In [9], the authors take a look at how the circular characteristics of the economy affect the future of industrial engineers. It is demonstrated that the industrial engineer of the future is one to master concepts of circular economy strategies. It is proposed that circular economy concepts be realized in curriculum through collaborative design project works.

\subsection{Projection}

Analysing trends in the industrial engineering profession is only the first step in developing the concept of industrial engineers of the future. The next step is to project those areas of the profession that are likely to take the forefront, in the years to come. This involves prediction of those skills and competences that are likely to see increased job market demand. In [10], authors explore the idea of predicting future needs of the industrial communication field. In [11], a method to measure educational alignment to industry is proposed, further alluding to the relevance of the topic. This study predicts that the following competences are critical for the industrial engineer of the future:

1. Innovation and entrepreneurship

2. Sustainable development

3. Digital technologies

Collectively, these three competences are identified to shape the industrial engineer of the future.

\subsubsection{Innovation and entrepreneurship}

The national and even global call for an improved entrepreneurship environment means that the economy can anticipate growth in small to medium enterprise establishments as well as innovation and development, especially from the youth population. In [12], authors show that as for engineering education, this call has largely been answered, with entrepreneurship education being integrated into engineering degrees. In [12], the authors analyse the impact of entrepreneurial competence in the engineer of the future, to identify and appreciate the role of entrepreneurship education in economic development. Results of the study indicate that the future of the engineering profession strongly demands entrepreneurial competences, especially at graduate level. 
In [13], the authors point out that over the past few decades, the engineering job market has generally become more competitive. The authors further show that trends indicate that the job market will in fact become even more competitive in the near and longterm future. It is therefore critical to invest in entrepreneurship competences for the future engineers. In [14], authors argue that entrepreneurial competences are so vital for the future engineer that there is need to globally standardize how entrepreneurial concepts are incorporated into engineering curriculum.

In [15], the authors actually argue that entrepreneurship education cannot be separated from engineering education. A successful career in engineering, as the world races Industry 4.0, would be heavily centred on entrepreneurship competences. In [16], authors in order to safeguard the career, propose the synchronization of the engineering and business courses. This is shown to potentially promote entrepreneurial competences towards the required level.

\subsubsection{Sustainable development}

The Sustainable Development Goal (SDG) initiative is a global movement and one that has massive influence on the economic future of South Africa, as with every other country. The SDG initiative calls for intensive transformation for every country, affecting the operations of the entire national value chain including government, private sector, industry, civil society and science [17] and has become the cornerstone of business across the world. Businesses are increasingly aligning more and more towards sustainable solutions, and massive investments are increasingly being channelled towards research into sustainable solutions for example in the field of electrical vehicles. Since the turn of the century, massive strides have already been made towards the SDG initiatives and it has never been more certain that sustainable development is the heart of the future global economy, as enterprises start to reflect sustainability concepts through internal objectives and visions. In [18], authors show that the concepts of environmental and social sustainability, are the most commonly discussed.

While the market is becoming more competitive, operational costs are generally increasing. This makes it important to be able to optimize business operations, systems or products. This includes improved loss control systems, price management, product development/improvement, resource management and so on. Sustainable development concepts are expected to be a significant part of the work of the industrial engineer of the future. In [19] authors reiterate that a cleaner/greener industry has huge economic implications and highlight that the growing advocacy for sustainable production will continue to grow into the future. In [20], the authors show that renewable energy projects have national-scale economic impact, and such projects deserve national support. The authors also highlight that the demand for renewable energy solutions will continue to rise into the future. In [21], authors conduct a survey on public statements of mining associations and the extent to which statements relating to sustainability are incorporated into policy, and the survey reveals that while the mining industry has allowed a sustainability shift, more needs to be done. The study shows that, out of 61 associations, 67 percent had public statements on sustainability.
In [22], the authors also highlight that sustainability concepts have been pivotal in the mining industry since the year 2010, and that it has become necessary for professionals in the mining industry to appreciate and accommodate sustainable mining practices. In [23], authors discuss how sustainable development is so key for the future that the concept of sustainable development should not be localized to the private sector only, or to engineering and science only. The authors show how, at national level economics, implementing strategic sustainable development objectives may contribute to improved trade deficit management.

In [24], the author discusses the steel-making process, revealing how the use of the by-products contributes to sustainable development. Literature suggests that slag from the iron and steel industries, when used to complement cement, improves the microstructure of built concrete. In [25], authors study the current state of the hotel industry and show that more innovation is required to meet the sustainability demands of the industry, especially given the sophistication of customer requirements. Innovative controls are required to improve waste and power management, to make operations more sustainable.

\subsubsection{Digital technologies}

Industry 4.0 places automation at the centre of industrialisation, and digital technologies form the basis for automation systems hence the need for emphasis on digital technologies for the industrial engineer of the future. The twentyfirst century is characterized by growing popularity of digital technologies, defined by electronic tools, machines, systems, and software that generate, process and utilize data. The manufacturing sector is particularly going through a fourth revolution and this calls for more strategic approaches to industrial engineering education, and engineering in general. In [26], authors discuss how Industry 4.0 calls for digital technologies, especially in the area of Internet of Things (IoT), big data, cloud computing as well as data analysis and processing.

In [27], the author highlights that in this digital era, there is more need to implement systems that can commercialize higher education research, that is to say, systems that can transfer academic work to industry. In [28], authors study the trends in industrial maintenance services and point out that the fourth industrial revolution will see the concept of 'big data' becoming key to efficient industrial maintenance management, in the near future. In the medical field, surgical processes have seen automation, patient profiles have been digitized for improved access to information, such as medical history [29]. In [30], authors, amidst the COVID-19 pandemic, discuss digital technologies that may ensure better patient isolation, by creating automated virtual centres to minimize physical crowding at hospitals and clinics.

Finance and economics have both been substantially transformed by digital technologies. In [31], authors propose the use of advanced digital mathematical models and algorithms to assess the feasibility of engineering projects in order to support capital investment decision making. The proposed digital system is proven to be robust and able to process large amounts of diverse data. In [32], the authors trace the age of digital marketing technologies in the sales of industrial services. The authors illustrate that smart systems have gained massive ground in 
industry over the past decade and such technologies are still on the rise.

In [33], internet marketing is compared to traditional marketing and it is shown that internet marketing is a superior marketing tool in today's economy, and more so, tomorrow's. In agriculture, the present and future have never been more digital. Agriculture across the entire planet has been redefined by automation and robotics, information communication technologies, drones and sensors as well as digital surveys and advanced climate and environment modelling technologies. In [34], authors show how digital technologies have brought about solutions to the challenge of access to the market in farming, especially for the small-holder farmer. In [35], authors introduce the concept of 'Agriculture 4.0' with alignment to that of 'Industry 4.0', highlighting that the era of Agriculture 4.0 has begun and is characterized by advanced digital and biotechnological innovations in agriculture. As the world becomes more and more digital, the threat to information security however, worsens. Cyber-security is therefore a key area of technology today, and even more, in future, as new cyber-security threats continue to evolve [36].

We therefore identify a gap, that while it is evident that the industrial engineering profession is dynamic, no structures have been set up yet, to explicitly allow the concept of future industrial engineers to be incorporated into curriculum.

\section{Methodology}

The Fourth Industrial Revolution (Industry 4.0) is summarised by automation, smart technology solutions, internet of things and improved machine communication. Understanding the requirements of Industry 4.0 is the first step in determining and developing the concept of the industrial engineer of the future. The requirements may be clearly spelt out by investigating the needs of the different players in this Industry 4.0 dimension. A survey is therefore conducted to establish the skill and knowledge requirements of the industrial engineer of the future, based on current dynamics of the industry. The survey responses are a collection from fifty-eight South African and Zimbabwean engineering and technological companies, $65 \%$ being start-ups. The idea of including more start-ups in the survey is not only the fact that start-ups are easier to reach (the Harare Institute of Technology alone host a start-up hub with over fifteen enterprises) but also that such are the players expected to reshape the industry of tomorrow.

A quantitative approach is taken for the study, involving the analysis of the distribution of the future skill and knowledge needs of the engineering business processes of the respondent companies. A quantitative approach is adopted because real data from real enterprise specialising in various engineering works and projects will reflect a realistic and measurable index of the requirements of the future engineer.

The feasibility of this approach can be referenced to a study conducted in [10] which reviews technological trends of industry 4.0 and the impact thereof, on industrial communication.

The following assumptions are made:

- As current players in industry, engineering companies do provide reliable insight as to the futuristic trends in skill and knowledge requirements, based on the operations being carried out today, and the possible improvements.

- $\quad$ Start-up type companies represent industrial players in a drive to penetrate the industry with innovative solutions and hence amplify the reflection of the future industry.

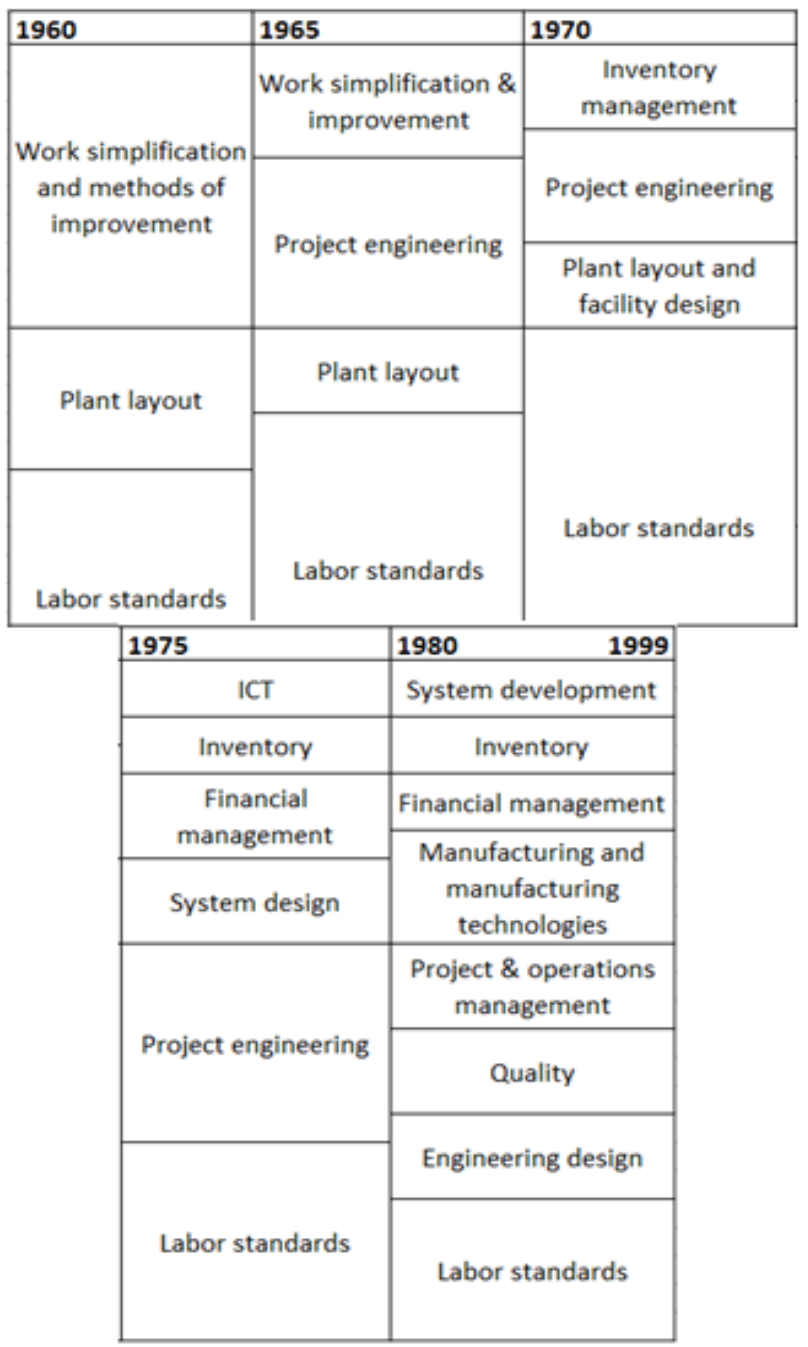

Figure 1: Twentieth century industrial engineering function trends - adopted from [2]

The illustration above proves that the industrial engineering profession is indeed under evolution. The next step is therefore to predict where this evolution is headed towards by means of survey data.

\subsection{Data collection}

Data is collected from an industrial survey with practising companies, to determine, from an operational perspective, the needs of the future industry. 


\subsection{Data evaluation}

To evaluate the data, a comparison is made, against a recent study which investigated the technological trends of industry 4.0 and the impact of these trends on industrial communication. Reference is also given against the general directives surrounding industry 4.0. The evaluation shows acceptable levels of data and method reliability.

\section{Discussion and findings}

The general trend of the past century is that industrial engineering saw a shift from industry/factory functions to more commercial functions. The industrial survey conducted in this work, with enterprises practising engineering, aims to extend the trends given in [2] beyond the year 2025, and also to close the gap partially, from the year 2000 to-date. It is established that the period between the year 2000 to-date was generally characterised by growing diversity and flexibility within the industrial engineering profession. This period saw a rise in demand, particularly, for such competences as those aligned to:

- financial sustainability

- environmental friendly business processes

- $\quad$ process, system or product optimisation

- $\quad$ risk and loss control

- $\quad$ product and system development

This trend can actually be cross-referenced to the general global developmental priorities and goals. Risk management and loss control in particular, are two areas that both the private sector and government have prioritised over the past two decades. The idea of loss control has been globally received as a means to increase profits, without necessarily increasing product pricing, especially given the competitiveness of today's market. Impacts of the United Nations Sustainable Development Goals (SDGs) have significantly affected industry across the planet, especially in terms of business management and operations. The decade from the year 2020 has been set as the 'Decade of Action', with respect to the SDGs and this global campaign is expected, and is already affecting industry. Consequently, this goes to affect several professions, with industrial engineers included. This makes it vital for the education system to incorporate and prioritise sustainability concepts. It is in fact common at present day, for job functions to involve duties to do with operational sustainability, for example an industrial engineer at a mining company will typically be tasked to develop systems to manage power usage. With growing popularity of the UN SDGs, the majority of project support initiatives today, as well as project funding schemes, both locally and internationally, are typically set to prioritise projects with elements of sustainability. Figure 2 is an extension to Figure 1, illustrating a forecast beyond the year 2025 in terms of industrial engineering skill and knowledge needs, based on the survey conducted.

Figure 2 depicts the functions that are predicted to top demand as far as the industrial engineering profession is concerned. It is seen that the key function areas of innovation, optimisation techniques, sustainability, automation, digital systems and business development score high in terms of demand. Innovation relates to business development and collectively form the basis for the business growth, especially in the case of starting and early www.astesj.com stage enterprises, such enterprises that today employ more people than formal established enterprises. Optimisation and automation relate to advanced industrial decision-making tools and digital technologies that empower machines to execute tasks in a manner that more effective, accurate or efficient than the human counterpart. This narrows down the key concepts to innovation, digital technologies and sustainable development.

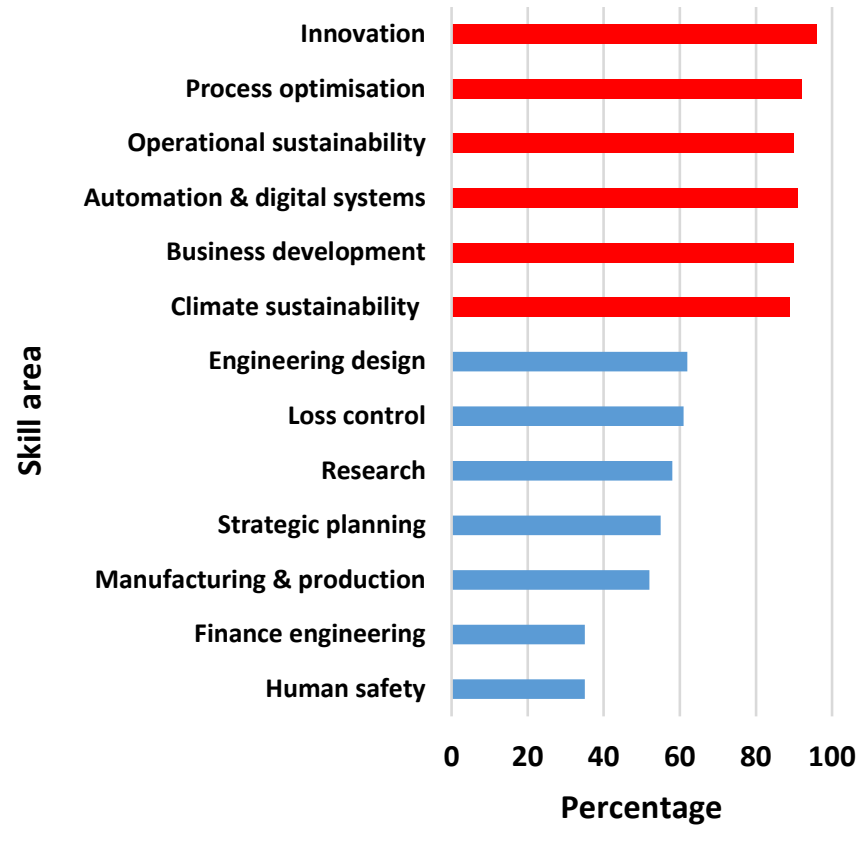

Figure 2: Extended industrial engineering function trends

The projections presented by Figure 2 call for the educational systems to incorporate the predicted elements into curriculum more explicitly. While curriculum is under constant management for the purpose of better addressing the evolving needs of the industry, this study proposes an improvement, characterised by prioritisation of some three aspects of industrial engineering education. The three aspects are:

1. Innovation and entrepreneurship

2. Sustainable development

3. Digital technologies

These economic aspects are projected to dominate the future of the industrial engineering profession. Academic prioritisation of these aspects is expected to better orient the industrial engineer for the future. The discussion presented in this work is summarised by Figure 3, which illustrates the three aspects above as pillars for the future of industrial engineering students.

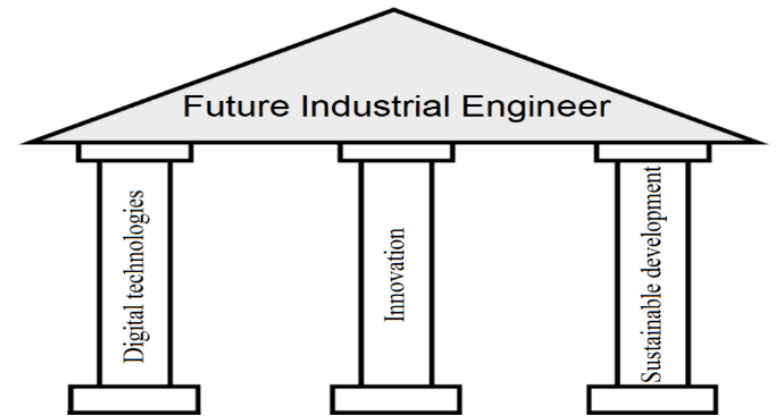

Figure 3: Illustration of the concept of the industrial engineer of the future 
As with any structure, a foundation is necessary. This foundation is proposed from the perspective of graduate attributes. In [37], authors define graduate attributes as the qualities that a university or college community agrees to develop in the students during their study period at the respective institution. These attributes exceed academic competences and technical skills reaching over to qualities that prepare graduates for social good, in a global economy that is dynamic and with an unknown future. The most common and typical graduate attributes include:

- Effective communication

- $\quad$ Strong citizenship

- Leadership skills

- $\quad$ Problem solving skills

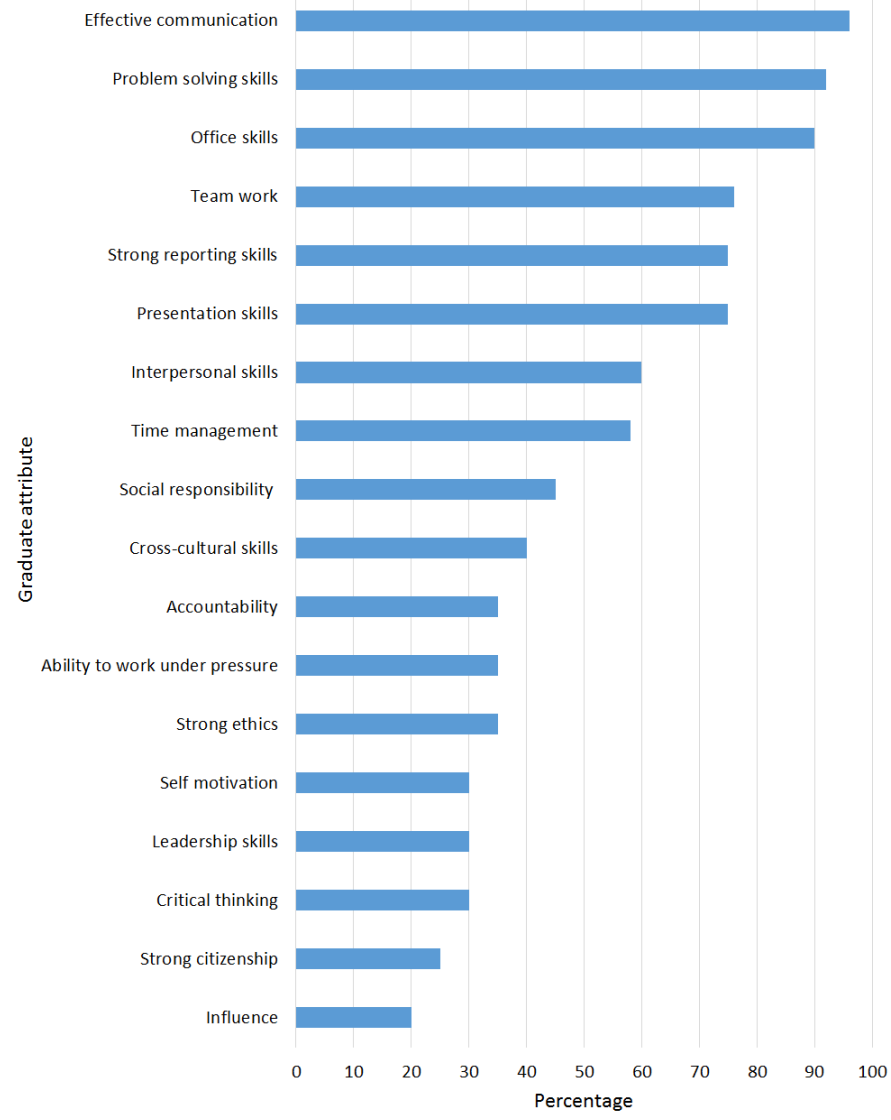

Figure 4: Graduate attribute distribution

Today, graduate attributes have become a core element of tertiary learning outcomes and integration of generic attributes into university or college curriculum is on a world-wide rise, especially towards promoting development of skills that better equip students for the work environment and also for self-employment. Higher learning institutions have therefore over the past few decades, placed 57 increasing value on developing graduate attributes and ensuring that the attributes are reflected within graduates.

In [38], authors show that one challenge is that some lecturers or educators may not see or perceive the value and essence of developing graduate attributes and may thus consequently be reluctant to realise graduate attribute obligations throughout their teaching experience. For graduate attributes to be effectively implemented, curriculum is one place to look at.

In this study, an investigation into the trends of distribution of demand for graduate attributes is made for the industrial engineering profession. The study outline is to collect data from industry through a survey to determine the attributes that employers seek when recruiting industrial engineers. Input data for this survey is collected from an on-line job advertisement platform. For each industrial engineering job post, recruiters typically highlight the following:

- job description

- minimum qualification

- desired personal attributes

Such on-line platforms therefore provide diverse information for survey. In [39], authors show that is it possible and effective, to collect education management control data from job advertisement platforms. One hundred job post samples are processed to produce the distribution depicted by Figure 4.

Figure 4 shows that, from the attribute study conducted, the communication attribute is most critical for the industrial engineer. In [40], authors conduct a study to determine the most demanded gradate attribute. By cross-referencing the survey results in Figure 4 above (industrial engineering profession), with those presented in [40] (general multi-profession study), it is possible to determine any reciprocity as well as any data disagreement too. The strategy is to therefore compare the top attributes sought by industry, as presented in [40], against findings from Figure 4. Table 1 outlines the comparison.

Table 1: Comparison of findings from graduate attribute study

\begin{tabular}{|l|l|}
\hline Literature [40] & Figure 4 \\
\hline 1. communication & 1. communication \\
2. teamwork & 2. problem-solving \\
3. citizenship & 3. office skills \\
4. critical thinking & 4. teamwork \\
5. problem-solving & 5. reporting skills \\
\hline
\end{tabular}

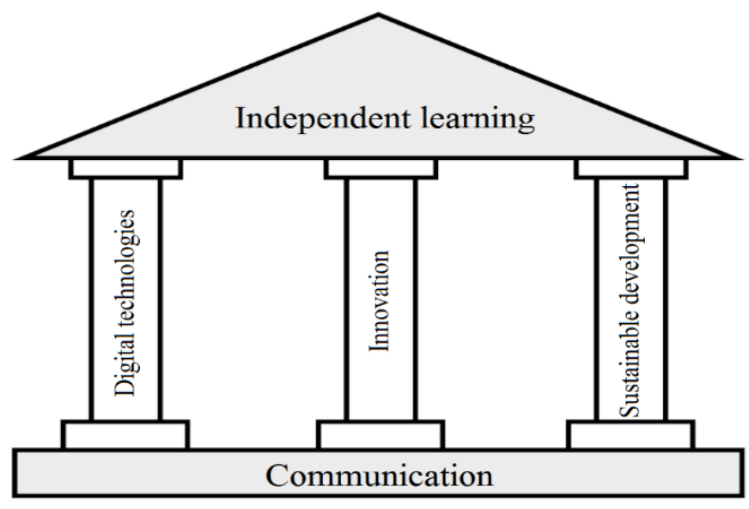

Figure 5: Final illustration of the concept of the industrial engineer of the future 
It can be observed from this combined analysis, that the communication attribute is of highest priority, not only from the industrial engineering perspective, but also in a general sense. The problem solving and teamwork attributes are also of high priority. Analysing the attributes presented in Table 1 deeper, reveals that of the top attributes, the aspect of communication is in fact represented in 50 percent of the given top attributes.

The pillar diagram is therefore revised to present the industrial engineer of the future as depicted by Figure 5 below.

This figure shows that the industrial engineer of the future is one to master digital technologies, innovation and sustainable development, over and above, the attribute of effective communication. The advantage of the proposed concept is that the concept interprets the state of the real industry of today to produce a pathway for students to follow today, in order to fit into industry tomorrow and to make the necessary knowledge and skill contribution that will be required. This study considers real industry data (survey). The disadvantage is that industry, economics and society being dynamic, the requirements of today and those of 2030 may not be the same, hence the need for an evolutionary approach as an extension to the proposed solution.

\subsection{Way forward}

Today, there is worldwide concern for sustainable development, with emphasis on the 'three Ps' that is, the People, Planet and Profit, where businesses ensure not only the well-being of shareholders through profits, but also the well-being of the people and the planet. This study proposes curriculum to incorporate these three Ps. In the context of South Africa, the main economic, environmental, social and political factors (in the sense of sustainability) that need to be considered are proposed as:

- Women empowerment

- Youth empowerment

- Graduate unemployment

- Electricity shortage

- Environmental pollution

- Increasing fuel price

- Climate change

- Import substitution (indigenisation)

It is proposed that these topics become mark points for student work, especially projects. Design solutions for example, could be evaluated from an environmental perspective, towards determining potential impact on the planet.

In the case of innovation, over and above the inclusion of an innovation/entrepreneurship course within engineering curriculum, it is noted through this study, that there is need to improve the entrepreneurial experience of the engineering student during the study process. To achieve this goal of promoting entrepreneurship through curriculum, this study proposes that a unique case-study approach be taken, where learners are tasked with a target number of practical industry-based freelance work projects, as part of the study experience. These projects are set to be sourced from online freelance work advertising platforms, reflecting the true nature of the needs of the industry. Each industrial engineering student is required, after completing a project, to present the project for evaluation in class, by both lecturers and students. The projects are then evaluated according to:

1. Project scope and objective

2. Technological aspect

3. Deliverables

\section{Complexity}

\section{Approach}

\section{Financial perspective}

This proposal ensures that innovation and entrepreneurship are better accounted for by curriculum, especially given the prevailing trends where entrepreneurship is rapidly growing as a source of employment across various industries.

\section{Conclusions}

The skill and knowledge requirements of any profession evolve over time, according to various contributing factors such technology, economics, politics and so. In order to maintain relevance of higher education, it is important to adapt education to the prevailing industrial requirements. It is even more important to actually predict where the industry requirements' evolution is headed, and to then manipulate higher education accordingly. In this study, the concept of the industrial engineer of the future is discussed. Based on an industrial survey, this study shows that there are three key knowledge areas which will shape the industrial engineer of the future. These three are innovation and entrepreneurship, sustainable development and finally, the digital technologies.

It is recommended that the industrial engineering education lifecycle takes these three knowledge areas as knowledge areas of high priority for the benefit of graduate industrial engineers. Future research is recommended to allow scheduled updates and trend analysis tools to measure the precision of the model of the industrial engineer of the future as predicted today.

\section{Conflict of Interest}

The authors declare no conflict of interest.

\section{References}

[1] R. Kumar, Industrial engineering, Jyothis Publishers, 2020, ISBN: 9353962854.

[2] M. Zandin, Industrial engineering handbook, vol. 5 McGraw Hill Companies, 2004. ISBN 49780070411029.

[3] P. Debney, "The engineer of the future is a centaur", The Institution of Structural Engineer, 98(1), 24-31, 2020.

[4] Y. Lobanova, "Basic guidelines, principles and psychological-pedagogical technologies of creation of the engineer of the future", Integrating Engineering Education and Humanities for Global Intercultural Perspectives. IEEHGIP 2020. Lecture Notes in Networks and Systems, vol 131. Springer, Cham, 2020, doi.org/10.1007/978-3-030-47415-7_66.

[5] R. Kumar, Industrial Engineering. Jyothis Publishers, 2020, ISBN: 978-935396-285-2.

[6] M. Wollschlaeger, T. Sauter, J. Jasperneite, "The future of industrial communication: Automation networks in the era of the internet of things and industry 4.0", IEEE industrial electronics magazine, 11(1), 17-27, 2017, doi: 10.1109/MIE.2017.2649104 
[7] L. G. Veraldo, M. B. Silva, J. Lourenco, C. Herculano, E. Soares, H. Sampaio, J. L. Rosa, "Assessment method of the competencies of industrial engineer in an interdisciplinary project, in 12th International CDIO Conference", CDIO Project in Progress Contributions, Turku, Finland, 2016.

[8] C. Butts, H. Valentine, H, Building on our past to engineer the future, Peanut Science, 46(1A), 82-90, 2019 doi: 10.3146/0095-3679-46.1A.82.

[9] J. Gonzalez-Dominguez, G. Sanchez-Barroso, F. Zamora-Polo, J. GarciaSanz-Calcedo, "Application of circular economy techniques for design and development of products through collaborative project-based learning for industrial engineer teaching", Sustainability, 12(11), 2020, doi.org/10.3390/su12114368.

[10] M. Wollschlaeger, J. Thilo, "The future of industrial communication: Automation networks in the era of the internet of things and industry 4.0", IEEE, 11(1), 17 - 27, 2017. DOI: 10.1109/MIE.2017.2649104.

[11] P. N. Chikasha, K. Ramdass, K. Mokgokloa, R. Maladzhi, "Aligning industrial engineering education with industry through atomic curriculum manipulation", The South African Journal of Industrial Engineering, 31(4), $92-103,2020$.

[12] V. Barba-Sanchez, C. Atienza-Sahuquillo, "Entrepreneurial intention among engineering students: The role of entrepreneurship education", European Research on Management and Business Economics, 24(1), 53-61, 2018, doi.org/10.1016/j.iedeen.2017.04.001

[13] M. Martinez, X. Crusat, "The entrepreneurship journey: Fostering engineering students entrepreneurship by startup creation", 2019 IEEE Global Engineering Education Conference (EDUCON), Dubai, 8-15 (April) 2019, 120-123, doi: 10.1109/EDUCON.2019.8725115.

[14] C. L. Entika, M. K. Jabor, S. Mohammad, S. Osman, "Defining the meaning of entrepreneurship education for future engineering graduates", 2017 7th World Engineering Education Forum (WEEF), Kuala Lumpur, (November), 2017, 290-293, doi: 10.1109/WEEF.2017.8467166.

[15] C. Hixson, M. Paretti, "Unpacking why engineering faculty members believe entrepreneurship is valuable for engineering education", Advances in Engineering Education, 7(1), 2018.

[16] J. E. Lugo, M. L. Zapata-Ramos, M. J. Perez-Vargas, "Promotion of innovation and entrepreneurship in engineering design by synchronizing engineering and business school courses", in International Design Engineering Technical Conferences and Computers and Information in Engineering Conference, 50138, American Society of Mechanical Engineers, 2016, doi: 10.1115/DETC2016-59701

[17] J. D. Sachs, G. Schmidt-Traub, M. Mazzucato, D. Messner, N. Nakicenovic, J. Rockstrom, "Six transformations to achieve the sustainable development goals", Nature Sustainability, 2(9), 805-814, 2019.

[18] E. Aimagambetov, R. Bugubaeva, R. Bespayeva, N. Tashbaev, "Model of sustainable development of tourism industry in Kazakhstan (regional perspective)", Public Policy and Administration, 16(2), 179-197, 2017, doi:10.13165/VPA-17-16-2-02

[19] G. C. Oliveira Neto, J. M. F. Correia, P. C. Silva, A. G. Oliveira Sanches, W. C. Lucato, "Cleaner production in the textile industry and its relationship to sustainable development goals", Journal of cleaner production, 228, 15141525, (August) 2019, doi.org/10.1016/j.jclepro.2019.04.334

[20] S. R. Paramati, N. Apergis, M. Ummalla, "Dynamics of renewable energy consumption and economic activities across the agriculture, industry, and service sectors: evidence in the perspective of sustainable development", Environmental Science and Pollution Research, 25(2), 1375-1387, 2018, doi: 10.1007/s11356-017-0552-7.

[21] V. Vivoda, D. Kemp, "How do national mining industry associations compare on sustainable development?" The Extractive Industries and Society, 6(1), 22-28, 2019, doi: 10.1016/j.exis.2018.06.002.

[22] J. Caron, S. Durand, H. Asselin, "Principles and criteria of sustainable development for the mineral exploration industry", Journal of Cleaner Production, 119, 215-222, (April) 2016, doi.org/10.1016/j.jclepro.2016.01.073.

[23] M. Alawin, M. Oqaily, "Current account balance, inflation, industry and sustainable development in Jordan", Revista Galega de Economia, 26(3), 45-56, 2017.

[24] I. Yuksel, A review of steel slag usage in construction industry for sustainable development, Environment, Development and Sustainability, 19(2), 369-384.

[25] F. Melissen, E. Cavagnaro, M. Damen, A. Duweke, "Is the hotel industry prepared to face the challenge of sustainable development?" Journal of Vacation Marketing, 22(3), 227-238, 2016, doi: $10.1177 / 1356766715618997$

[26] Y. Li, J. Dai, L. Cui, "The impact of digital technologies on economic and environmental performance in the context of industry 4.0: A moderated mediation model", International Journal of Production Economics, 2020,
107777.

[27] W. Sutopo, "The roles of industrial engineering education for promoting innovations and technology commercialization in the digital era", in IOP Conference Series: Materials Science and Engineering, 495, 012001, IOP Publishing, 2019

[28] S. Marttonen-Arola, D. Baglee, "Adoption of information-based innovations in industrial maintenance", in ISPIM Conference Proceedings, 1-16, The International Society for Professional Innovation Management (ISPIM), 2019.

[29] S. Kalajdziski, N. Ackovska, ICT Innovations 2018. Engineering and Life Sciences: 10th International Conference, ICT Innovations, Ohrid, Macedonia, (September), 940, 2019, Springer, ISBN 978-3-030-00825-3

[30] M. Javaid, A. Haleem, R. Vaishya, S. Bahl, R. Suman, A. Vaish, "Industry 4.0 technologies and their applications in fighting covid-19 pandemic", Diabetes \& Metabolic Syndrome: Clinical Research \& Reviews, 2020, doi: 10.1016/j.dsx.2020.04.032

[31] Y. Kirillov, E. Dragunova, A. Kravchenko, A. Dorofeeva, "Innovations in engineering: analysis of the increase effect in net present value," IOP Conference Series Materials Science and Engineering, 2020, 843:012018.

[32] M. Classen, T. Friedli, T., "Value-based marketing and sales of industrial services: A systematic literature review in the age of digital technologies", Procedia CIRP, 83, 1-7, 2019.

[33] K. O. Kayumovich, F. S. Annamuradovna, "The main convenience of internet marketing from traditional marketing", Marketing Academy, 1(52). doi: 10.24411 / 2412-8236-2020-10101.

[34] U. Deichmann, A. Goyal, Y. Mishra, Y, Will digital technologies transform agriculture in developing countries? The World Bank, 2016, doi.org/10.1111/agec. 12300 .

[35] Y. Klerkx, D. Rose, D. Dealing with the game-changing technologies of agriculture 4.0: How do we manage diversity and responsibility in food system transition pathways? Global Food Security, 24, 2020, 100347. doi.org/10.1016/j.gfs.2019.100347.

[36] E. H. Peerzadah, I. Kaur, R. Banu, Multifaceted aspects of advanced innovations in engineering and technology, IJRECE, 7(2), 2019, ISSN: 2348-2281 (online).

[37] D. Kember, C. Hong, V. W. Yau, S. A. Ho, "Mechanisms for promoting the development of cognitive, social and affective graduate attributes," Higher education, 74(5), 799-814, 2017, doi:10.1007/s10734-016-0077-x.

[38] R. Moalosi, M. T. Oladiran, J. Uziak, "Students perspective on the attainment of graduate attributes through a design project," Global journal of engineering education, 14(1), 40-46, 2012.

[39] E. Pitukhin, A. Varfolomeyev, A. Tulaeva, "Job advertisements analysis for curricula management: the competency approach," in 9th Annual International Conference of Education, Research and Innovation Proceedings, [Seville], 2026-2035, 2016, doi:10.21125/iceri.2016.1456.

[40] B. Oliver, T. Jorre de St Jorre, "Graduate attributes for 2020 and beyond: Recommendations for australian higher education providers," Higher Education Research \& Development, 37(4), 821-836, 2018 , doi.org/10.1080/07294360.2018.1446415. 